\title{
Toxicities of Triclosan, Phenol, and Copper Sulfate in Activated Sludge
}

\author{
Rosalind A. Neumegen, ${ }^{1}$ Amadeo R. Fernández-Alba, ${ }^{2}$ Yusuf Chisti ${ }^{1}$ \\ ${ }^{1}$ Institute of Technology and Engineering, Massey University, Private Bag 11222 , \\ Palmerston North, New Zealand \\ ${ }^{2}$ Department of Analytical Chemistry, University of Almería, E-04071 Almería, Spain
}

Received 27 September 2004; accepted 7 December 2004

\begin{abstract}
The effect of toxicants on the BOD degradation rate constant was used to quantitatively establish the toxicity of triclosan, phenol, and copper (II) against activated sludge microorganisms. Toxicities were tested over the following ranges of concentrations: $0-450 \mathrm{mg} / \mathrm{L}$ for phenol, $0-2 \mathrm{mg} / \mathrm{L}$ for triclosan, and $0-35 \mathrm{mg} / \mathrm{L}$ for copper sulfate (pentahydrate). According to the $\mathrm{EC}_{50}$ values, triclosan was the most toxic compound tested $\left(E_{50}=1.82 \pm 0.1 \mathrm{mg} / \mathrm{L}\right)$, copper (II) had intermediate toxicity $\left(E C_{50}=\right.$ $18.3 \pm 0.37 \mathrm{mg} / \mathrm{L})$, and phenol was the least toxic $\left(\mathrm{EC}_{50}=270 \pm 0.26 \mathrm{mg} / \mathrm{L}\right)$. The presence of $0.2 \%$ DMSO had no toxic effect on the activated sludge. The toxicity evaluation method used was simple, reproducible, and directly relevant to activated sludge wastewater treatment processes.
\end{abstract}

(C) 2005 Wiley Periodicals, Inc. Environ Toxicol 20: 160-164, 2005.

Keywords: toxicity testing; activated sludge; biochemical oxygen demand (BOD); triclosan; phenol; copper sulfate

\section{INTRODUCTION}

Toxicity is the potential of a substance to adversely affect live organisms. Microorganisms responsible for BOD (biochemical oxygen demand) breakdown in activated sludge wastewater treatment processes react to the presence of toxicants. Responses displayed include reduced rates of respiration, biomass generation, and BOD degradation. These effects of toxicants lead to failed discharge contents (Arretxe et al., 1997; Davies, 2002). Because most of the world's wastewater is treated by the activated sludge process, assessing the toxicity of pollutants to activated sludge microorganisms is important (Ren and Frymier, 2002). Toxicity data specific to activated sludge microorganisms is scarce. This work reports on the toxicity of three representative chemicals against a mixed culture of activated sludge microorganisms. Toxicity was assessed by directly observ-

\footnotetext{
Correspondence to: Y. Chisti; e-mail: Y.Chisti@massey.ac.nz

Published online in Wiley InterScience (www.interscience.wiley.com). DOI 10.1002/tox.20090
}

ing the effects of toxicants on the BOD degradation activity of the cultures.

Many toxicity assays are available (Kapanen and Itavaara, 2001; Fernández-Alba et al., 2002a, 2002b), but few are directly relevant to activated sludge microorganisms. For example, the commonly used Microtox ${ }^{\mathrm{TM}}$ and Biotox ${ }^{\mathrm{TM}}$ assays are based on marine luminous bacteria (Kahru et al., 1996; Fernández-Alba et al., 2002a, 2002b; Ren and Frymier, 2002) that are not representative of activated sludge microbes. The single-species Shk1 assay based on the Shk1 bioluminescent bacterium is insufficiently representative of waste-degrading mixed microbial populations, even though the Shk1 organism originated from a wastewater treatment plant (Ren and Frymier, 2002).

Toxicity can be classified according to exposure time (acute or chronic), mode of effect (death, growth, reproduction), or effective response (lethal, sublethal) (Kapanen and Itavarra, 2001). Commonly used measures of toxicity include $\mathrm{LC}_{50}, \mathrm{EC}_{50}, \mathrm{IC}_{50}$, and MIC. $\mathrm{LC}_{50}$ (lethal concentration) is the concentration of a toxicant that kills $50 \%$ of a test population for a given exposure duration. $\mathrm{EC}_{50}$ 
(effective concentration) is the concentration of a given compound that reduces the specified effect to half that of the original response. $\mathrm{IC}_{50}$ (inhibitory concentration) is analogous to $\mathrm{EC}_{50}$, whereas $\mathrm{MIC}$ (minimum inhibitory concentration) is the lowest concentration of the toxicant needed to produce an inhibitory effect. $\mathrm{LC}_{50}$ and $\mathrm{EC}_{50}$ are measures of acute toxicity (Kapanen and Itavaara, 2001). For the purpose of this work, $\mathrm{EC}_{50}$ was defined as the concentration of a toxicant required to cause a $50 \%$ reduction in the BOD degradation rate constant, $k$, compared to the control (i.e., no toxicant added).

Although variants of the BOD method have been used for evaluating the toxicity of pollutants (Mowat, 1976; Busch, 1982; Ademoroti, 1988), toxicity results were generally described in terms of the fractional reduction in BOD removal caused by the presence of the toxicant (Gray, 2004) in comparison with a control (i.e., no toxicant present). This approach considered only the final BOD values in estimating toxicity, not the rate of BOD degradation. In the present study we used a statistically robust approach that measured the effect of the toxicants on the BOD degradation rate constant in order to determine toxicity. This approach is comparable to the data evaluation methods used in other well-established toxicity assays such as the Microtox $^{\mathrm{TM}}$ and Biotox ${ }^{\mathrm{TM}}$ assays.

Three representative compounds were used to assess the ability of the BOD assay as a measure of toxicity. The compounds were phenol, a known problem toxicant (Allsop et al., 1993) in activated sludge plants; triclosan, a widely used antibacterial agent that is added to toothpastes, deodorant soaps, dishwashing detergents, and various other consumer and household products; and copper sulfate, an inorganic metal salt commonly used in various pesticides and other applications.

\section{MATERIALS AND METHODS}

\section{Chemicals, Wastewater, and Mixed Culture}

The following chemicals were used in the toxicity assessments: phenol (Ajax Chemicals, Auckland, New Zealand), copper (II) sulfate $\left(\mathrm{CuSO}_{4} \cdot 5 \mathrm{H}_{2} \mathrm{O} ;\right.$ Ajax Chemicals, Auckland, New Zealand), and triclosan [5-chloro-2(2,4dichlorophenoxy)phenol or 2,4,4'-trichloro-2'-hydroxydiphenyl ether; courtesy of Colgate Palmolive, Petone, New Zealand; distributed by Chengdu GT Biochem Co., Ltd., Chengdu, China; the grade used met the USP24 standard].

Artificial wastewater was made by dissolving the following components in distilled water (1 L): $0.6 \mathrm{~g}$ of lactose (BDH, England), $0.78 \mathrm{~g}$ of skim milk powder, and $0.72 \mathrm{~g}$ of whole milk powder.

An acclimated mixed culture, or "seed," originally sourced from a Massey University duck pond was the toxicity test system. The acclimatized culture was maintained in a 1-L (700-mL working volume) aerated bioreactor held at $25^{\circ} \mathrm{C}$. The culture was fed every 7 days after removal of the seed aliquot. The volume removed was replaced with an equal volume of the artificial wastewater, and any evaporative loss was made up with distilled water. The seed used in the tests was always harvested on the seventh day after feeding. Use of a highly consistent "artificial" or "synthetic" consortium of activated sludge microorganisms is a well-established practice in measuring the degradation kinetics of pollutants (Kwan, 1988).

\section{Biochemical Oxygen Demand (BOD) Assay}

The toxic effects of the various compounds were evaluated individually using the 5-day $\mathrm{BOD}\left(\mathrm{BOD}_{5}\right)$ assay. The wastewater was prepared fresh and diluted by mixing $800 \mathrm{~mL}$ of distilled water with $200 \mathrm{~mL}$ of wastewater. All experiments used the diluted wastewater. The toxicities were evaluated for the following ranges of concentrations: 0-450 mg/L for phenol, 0-2 mg/L for triclosan, and 0 $35 \mathrm{mg} / \mathrm{L}$ for copper sulfate (pentahydrate). Depending on the required concentration, either the appropriate weight of toxicant was added directly to the final volume in each BOD bottle, or a small volume of an aqueous solution (in diluted wastewater) of the toxicant was added. For the sparingly soluble triclosan, a stock solution was made by first dissolving $2 \mathrm{mg}$ of triclosan in $2 \mathrm{~mL}$ of dimethylsulfoxide (DMSO; Auckland, New Zealand) and then the volume was made up to $1 \mathrm{~L}$ with diluted wastewater. This solution was made immediately prior to use.

The equipment used for the BOD test was the six-bottle capacity Hach Manometric BODTrak apparatus (Hach Company, Loveland, CO, USA). Each set of experiments used 12 BOD bottles and two separate BODTrak units. Each bottle contained a total volume of $95 \mathrm{~mL}$. Two bottles contained only the seed, and each of the remaining 10 bottles had $85.5 \mathrm{~mL}$ of diluted wastewater and $9.5 \mathrm{~mL}$ of seed (i.e., $10 \%$ seed by volume) and various concentrations of toxicants. Duplicate bottles were run for each concentration of toxicant. In addition, each experiment included duplicate control bottles (i.e., no added toxicant). For the triclosan experiment an additional control of wastewater and DMSO with no triclosan was run to observe the effect of DMSO on the culture. The BOD bottles were incubated at $20^{\circ} \mathrm{C}$ (Contherm Digital Series 5 cooled incubator) for 6 days, and the data were recorded continuously over the duration of the run. All assays were recorded in the $0-700 \mathrm{mg} / \mathrm{L} \mathrm{BOD}$ range. The nitrification reactions were suppressed by adding $0.16 \mathrm{~g}$ of a nitrification inhibitor (Hach Company, Loveland, CO, USA) to each BOD bottle.

The first-order degradation of BOD can be expressed as

$$
\frac{\mathrm{d}\left(\mathrm{BOD}_{\mathrm{r}}\right)}{\mathrm{d} t}=-k\left(\mathrm{BOD}_{\mathrm{r}}\right)
$$

where $\mathrm{BOD}_{\mathrm{r}}$ is the $\mathrm{BOD}$ remaining at time $t$ and $k$ is the degradation rate constant. If the total unknown initial BOD (or 

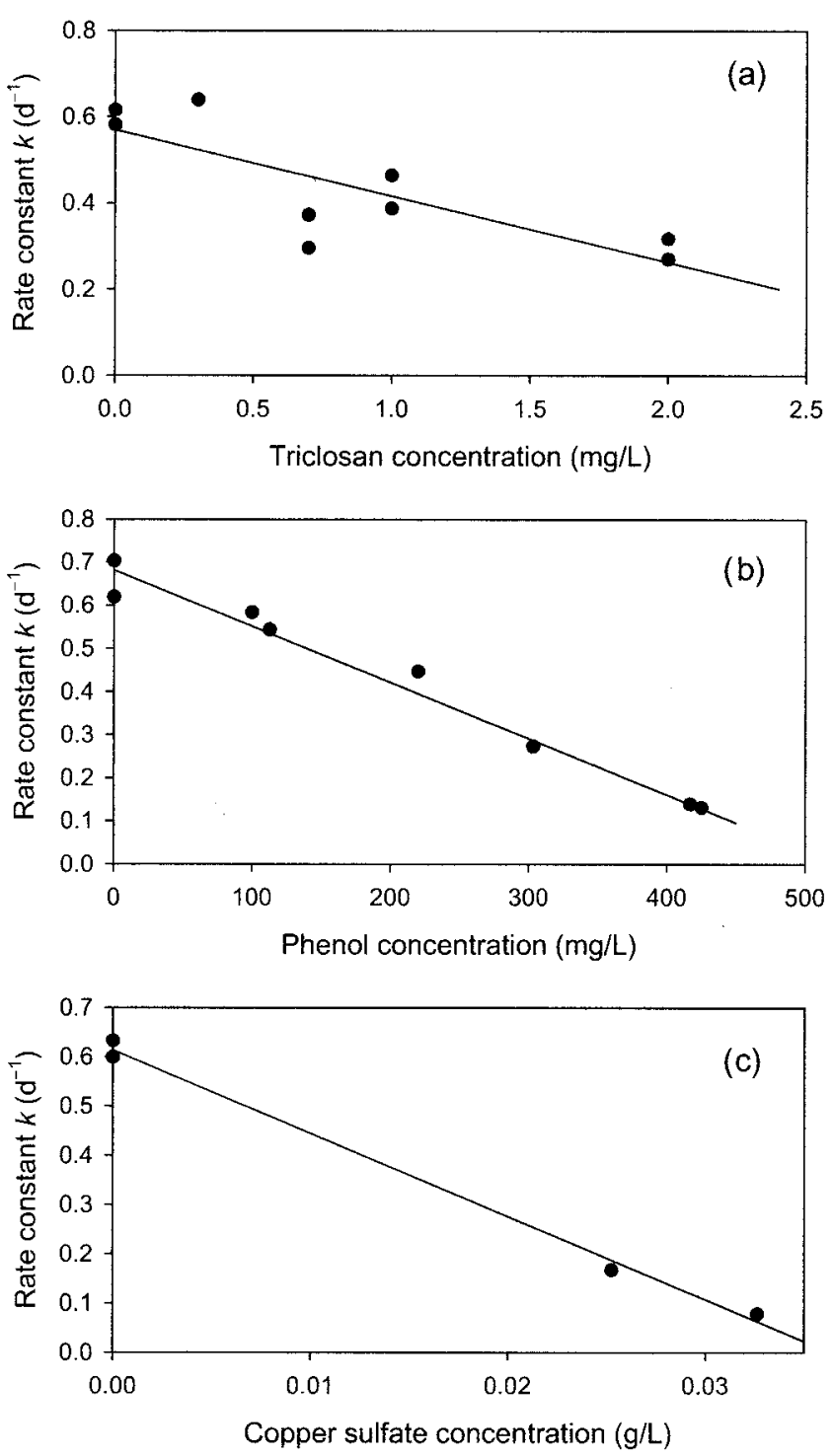

Fig. 1. BOD rate constant versus toxicant concentration: (a) triclosan, (b) phenol, (c) copper sulfate.

ultimate $\mathrm{BOD}$ ) is $\mathrm{BOD}_{\mathrm{u}}$, integrating Eq. (1) between the limits $\mathrm{BOD}_{\mathrm{r}}=\mathrm{BOD}_{\mathrm{u}}$ at $t=0$ and $\mathrm{BOD}_{\mathrm{r}}=\mathrm{BOD}_{\mathrm{r}}$ at $t=t$, yields

$$
\ln \frac{\mathrm{BOD}_{\mathrm{r}}}{\mathrm{BOD}_{\mathrm{u}}}=-k t
$$

or

$$
\mathrm{BOD}_{\mathrm{r}}=\mathrm{BOD}_{\mathrm{u}} \mathrm{e}^{-k t}
$$

The experimental measurements of BOD actually provide the value of $\mathrm{BOD}_{\mathrm{t}}$, that is, the $\mathrm{BOD}$ consumed by time $t$ and not $\mathrm{BOD}_{\mathrm{r}}$. $\mathrm{BOD}_{\mathrm{r}}$ can be eliminated from Eq. (3) because, for a closed sample, $\mathrm{BOD}_{\mathrm{t}}, \mathrm{BOD}_{\mathrm{u}}$, and $\mathrm{BOD}_{\mathrm{r}}$ are related as follows:

$$
\mathrm{BOD}_{\mathrm{t}}=\mathrm{BOD}_{\mathrm{u}}-\mathrm{BOD}_{\mathrm{r}}
$$

From Eqs. (3) and (4), there is the following expression:

$$
\mathrm{BOD}_{\mathrm{t}}=\mathrm{BOD}_{\mathrm{u}}-\mathrm{BOD}_{\mathrm{u}} \mathrm{e}^{-k t}
$$

Eq. (5) and the measured $\mathrm{BOD}_{\mathrm{t}}$ versus $t$ data can be used to calculate the rate constant $k$ and, if necessary, the $\mathrm{BOD}_{\mathrm{u}}$. The well-known least-squares method was used to estimate the $k$ values from the measured data. A reduced data set with measurements taken at 0.4-day intervals was used in all calculations.

Duplicate bottles at each concentration and within each set of tests were used to evaluate the reproducibility and reliability of the assay technique. The variance in the seed culture was determined by the standard deviation in the seed rate constant, $k$ (without added toxicants) and using data from six independent control experiments. The toxicity was expressed as $\mathrm{EC}_{50}$, or the concentration of the toxicant that caused a $50 \%$ reduction in the first-order BOD rate constant relative to the value in the absence of the toxicant. The $\mathrm{EC}_{50}$ value was determined by plotting graphs of the rate constant $(k)$ versus the concentration of toxicant added to BOD bottles. Representatives graphs are shown in Figure 1. A linear regression line was plotted through the data. The regression equation was then used to calculate the concentration of toxicant that corresponded to a $k$ value that was $50 \%$ of the control value (i.e., no toxicant present). The $95 \%$ confidence limits of the mean values were calculated using the equation

Confidence limits

$$
=\text { mean rate constant } \pm\left[\text { standard deviation } \times t / n^{0.5}\right]
$$

where $t$ is the Student's $t$ value at $T_{0.05}(n-1)$ and $n$ is the number of measurements.

\section{RESULTS AND DISCUSSION}

The $\mathrm{EC}_{50}$ values measured by the BOD method are shown in Table I, column 2, for the three toxicants. For comparison, Table I also shows the representative $\mathrm{EC}_{50}$ values from the literature for the same toxicants measured with a variety of other assay systems. Based on the $\mathrm{BOD} \mathrm{EC}_{50}$ values, triclosan was the most toxic of the three compounds tested and phenol the least toxic. The literature toxicity data were generally consistent with this trend, except that the toxicity of copper sulfate varied a great deal depending on the measurement system used. The Microtox ${ }^{\mathrm{TM}}$ and Biotox ${ }^{\mathrm{TM}}$ 
TABLE I. Comparison of measured and literature $\mathrm{EC}_{50}$ values

\begin{tabular}{|c|c|c|c|c|}
\hline Toxicant & $\begin{array}{c}\mathrm{EC}_{50} \text { Calculated } \\
(\mathrm{mg} / \mathrm{L})\end{array}$ & $\begin{array}{l}\mathrm{EC}_{50} \text { Literature } \\
\text { values }(\mathrm{mg} / \mathrm{L})\end{array}$ & Organism/Test Used & Reference \\
\hline \multirow[t]{6}{*}{ Triclosan } & $1.82 \pm 0.1$ & 0.4 & Daphnia magna, $\mathrm{EC}_{50}$ & Jones et al. (2002) \\
\hline & & 0.2 & Algae, $\mathrm{EC}_{50}$ & Jones et al. (2002) \\
\hline & & 0.34 & Daphnia magna, $\mathrm{EC}_{50}, 48 \mathrm{~h}$ & Orvos et al. (2002) \\
\hline & & 0.001 & Algae (Scenedesums), $\mathrm{EC}_{50}, 96 \mathrm{~h}$ & Orvos et al. (2002) \\
\hline & & 0.26 & Fathead minnow, $\mathrm{LC}_{50}, 96 \mathrm{~h}$ & Orvos et al. (2002) \\
\hline & & 0.37 & Bluegill, $\mathrm{LC}_{50}, 96 \mathrm{~h}$ & Orvos et al. (2002) \\
\hline \multirow[t]{6}{*}{ Phenol } & $270 \pm 0.26$ & 482 & $\begin{array}{l}\text { Shk1 assay, } \\
\text { bioluminescent bacterium } \mathrm{EC}_{50}\end{array}$ & Ren and Frymier (2002) \\
\hline & & $1.8 \mathrm{mmol} / \mathrm{L}$ & 2,4-dimethyl phenol, $\mathrm{IC}_{50}$ & Hall et al. (1996) \\
\hline & & $0.19 \mathrm{mmol} / \mathrm{L}$ & 2,5-dichlorophenol, $\mathrm{IC}_{50}$ & Hall et al. (1996) \\
\hline & & 107.4 & Biotox $^{\mathrm{TM}}, \mathrm{EC}_{50}, \min$ & Kahru et al. (1996) \\
\hline & & 17.3 & Microtox $^{\mathrm{TM}}, \mathrm{EC}_{50}, 5 \mathrm{~min}$ & Kahru et al. (1996) \\
\hline & & 28 & $\operatorname{Microtox}^{\mathrm{TM}}$ & Arretxe et al. (1997) \\
\hline \multirow[t]{8}{*}{$\mathrm{CuSO}_{4} \cdot 5 \mathrm{H}_{2} \mathrm{O}$} & $18.3 \pm 0.37$ & 449.42 & $\begin{array}{l}\text { Providencia rettgeri, } \\
\text { MIC, Oxoid broth }\end{array}$ & Hassen et al. (1998) \\
\hline & & 399.49 & $\begin{array}{l}\text { Pseudomonas aeruginosa, } \\
\text { MIC, Oxoid broth }\end{array}$ & Hassen et al. (1998) \\
\hline & & 49.94 & $\begin{array}{l}\text { Citrobacter freundii, } \\
\text { MIC, Oxoid broth }\end{array}$ & Hassen et al. (1998) \\
\hline & & $0.1-2.5$ & Harlequin fish, $\mathrm{LC}_{50}, 96 \mathrm{~h}$ & Merck (2001) \\
\hline & & $0.1-2.5$ & Rainbow trout, $\mathrm{LC}_{50}, 96 \mathrm{~h}$ & Merck (2001) \\
\hline & & 0.24 & Daphnia, $\mathrm{EC}_{50}, 48 \mathrm{~h}$ & Merck (2001) \\
\hline & & $0.1-2.5$ & Goldfish, $\mathrm{LC}_{50}, 96 \mathrm{~h}$ & Merck (2001) \\
\hline & & 0.39 & Pond snails, $\mathrm{LC}_{50}, 96 \mathrm{~h}$ & OMRI (2001) \\
\hline
\end{tabular}

bioluminescent bacteria were much more sensitive to phenol than was the activated sludge mixed culture. In contrast, the Shk1 bacterium, originally isolated from a wastewater treatment plant, was substantially less sensitive to phenol than was the mixed activated sludge.

Compared to almost all the other vertebrate and invertebrate test systems (Table I), the activated sludge microorganisms could withstand concentration of triclosan that was 5- to 1800-fold greater even though triclosan was highly toxic to these microorganisms. In view of the reported $\mathrm{EC}_{50}$ values of around $0.001 \mathrm{mg} / \mathrm{L}$, algae appear to be among the most sensitive test systems for triclosan.

Because triclosan was dissolved in $0.2 \%$ DMSO, it can be argued that the observed toxicity was partly associated with the solvent. Control experiments with $0.2 \%$ DMSO (no triclosan present) and with only the wastewater showed that DMSO had absolutely no toxicity at the concentration used. Thus, at $0.582 \pm 0.024 \mathrm{~d}^{-1}$, the BOD $k$ value for the DMSO control was statistically identical to a $k$ value of $0.6256 \pm 0.0421 \mathrm{~d}^{-1}$ determined for the wastewater controls. Similar results for DMSO were previously reported (Hernando et al., 2003).

The activated sludge culture was significantly more sensitive to copper $\left(\mathrm{EC}_{50}=18.3 \mathrm{mg} / \mathrm{L}\right)$ compared to the other bacteria (Table I), for which the $\mathrm{EC}_{50}$ values ranged from 50 to $450 \mathrm{mg} / \mathrm{L}$ (Hassen et al., 1998). Copper (II) can complex with components present in the test media (Hassen et al., 1998), and this effect can reduce the apparent toxicity, leading to the observation of elevated $\mathrm{EC}_{50}$ values. Some of the wide variation in the reported $\mathrm{EC}_{50}$ values for copper sulfate is explained by this effect.

The extremely high consistency of the different batches of seeds and wastewater was shown by a highly reproducible $k$ value of $0.6256 \pm 0.0421 \mathrm{~d}^{-1}$ for the controls. This average and the standard deviation were based on six independent measurements. The standard deviation was calculated as for a sample (i.e., $n-1)$.

\section{CONCLUSIONS}

The effect of toxicants on the BOD degradation rate constant was used to quantitatively establish the toxicity of triclosan, phenol, and copper (II) against activated sludge microorganisms. On the basis of the $\mathrm{EC}_{50}$ values, triclosan was the most toxic compound tested $\left(\mathrm{EC}_{50}=1.82 \pm\right.$ $0.1 \mathrm{mg} / \mathrm{L})$, copper (II) had intermediate toxicity $\left(\mathrm{EC}_{50}=\right.$ $18.3 \pm 0.37 \mathrm{mg} / \mathrm{L})$, and phenol was the least toxic $\left(\mathrm{EC}_{50}=\right.$ $270 \pm 0.26 \mathrm{mg} / \mathrm{L})$. The presence of $0.2 \%$ DMSO had no toxic effect on the activated sludge. The toxicity evaluation method used was simple, reproducible, and directly relevant to activated sludge wastewater treatment processes. The method did take 5 days to provide results, but this need 
not be a drawback if the toxicities are determined a priori using this method.

\section{REFERENCES}

Ademoroti CMA. 1988. The effect of metallic toxicants on biochemical oxygen demand (BOD) measurements. Biol Waste 24:259-265.

Allsop PJ, Chisti Y, Moo-Young M, Sullivan GR. 1993. Dynamics of phenol degradation by Pseudomonas putida. Biotechnol Bioeng 41:572-580.

Arretxe M, Heap JM, Christofi N. 1997. The effect of toxic discharges on ATP content in activated sludge. Environ Toxicol Water Qual 12:23-29.

Busch AW. 1982. Bioassay technique for relative toxicity in water pollution control. J Water Pollut Control Fed 54:1152-1154.

Davies P. 2002. Protecting receiving waters. Toxicity management at WWTWs. Water Waste Treatment. p 15.

Fernández-Alba AR, Hernando Guil MD, Díaz López G, Chisti Y. 2002a Comparative evaluation of the effects of pesticides in acute toxicity luminescence bioassays. Anal Chim Acta 451: 195-202.

Fernández-Alba AR, Hernando MD, Piedra L, Chisti Y. 2002b. Toxicity evaluation of single and mixed antifouling biocides measured with acute toxicity bioassays. Anal Chim Acta 456:303-312.

Gray NF. 2004. Biology of wastewater treatment. 2nd ed. London: Imperial College Press. p 93-31, 306.

Hall E, Sun B, Prakash J, Nirmalakhandan N. 1996. Toxicity of organic chemicals and their mixtures to activated sludge microorganisms. J Environ Eng 122:424-429.
Hassen A, Saidi N, Cherif M, Boudabous A. 1998. Resistance of environmental bacteria to heavy metals. Biores Technol 64:7-15.

Hernando MD, Ejerhoon M, Fernández-Alba AR, Chisti Y. 2003. Combined toxicity effects of MTBE and pesticides measured with Vibrio fischeri and Daphnia magna bioassays. Water Res 37:4091-4098.

Jones K, Fink-Gremmels J, Hardy T, Hay R, Klein W, Knapp A, Vives-Rego J, White I. 2002. Opinion on triclosan resistance. The Scientific Steering Committee, European Commission, Health and Consumer Protection Directorate-General, Brussels, Belgium.

Kwan KK. 1988. Synthetic activated sludge technique for toxicity assessment of chemicals and environmental samples. Toxic Assess 3:93-98.

Kahru A, Kurvet M, Kulm I. 1996. Toxicology of phenolic wastewater to luminescent bacteria Photobacterium phosphoreum and activated sludges. Water Sci Technol 33:139-146.

Kapanen A, Itavaara M. 2001. Ecotoxicity tests for compost applications. Ecotoxicol Environ Saf 49:1-16.

Merck, Inc. 2001. Copper (II) sulfate pentahydrate very fine crystals. Safety data sheet. p 1-6.

Mowat A. 1976. Measurement of metal toxicity by biochemical oxygen demand. J Water Pollut Control Fed 48:853-866.

OMRI. 2001. Copper sulphate, as an algaecide and invertebrate pest control. NOSB TAP (Technical Advisory Panel) Review. p 1-17.

Orvos DR, Versteeg DJ, Inauen J, Capdevielle M, Rothenstein A, Cunningham V. 2002. Aquatic toxicity of triclosan. Environ Toxicol Chem 21:1338-1349.

Ren S, Frymier PD. 2002. Estimating the toxicities of organic chemicals to bioluminescent bacteria and activated sludge. Water Res 36:4406-4414. 